\title{
Inequality and the political economy of education: An analysis of individual preferences in OECD countries
}

\author{
Marius R. Busemeyer \\ University of Konstanz, Germany
}

\begin{abstract}
Scholarly interest in the study of education from the perspective of political science has increased rapidly in the last few years. However, the literature focuses on comparing education politics at the country level, neglecting the analysis of micro-level foundations of education policies in terms of individual preferences and their interaction with macro contexts. This paper provides a first step in addressing this research gap, engaging in a multilevel analysis of survey data for a large number of OECD countries. The core research question is how institutional contexts - in this case socio-economic and educational inequalities - shape the micro-level association between the individual income position and support for education spending. The core finding is that these different dimensions of inequality have different implications at the micro level. Higher levels of socio-economic inequality enhance the conflict between the rich and the poor over public investments in education. By contrast, when access to higher levels of education is effectively restricted, the rich are more likely to support public education spending. This is because higher levels of educational stratification ensure that further public investments in education benefit the rich relatively more than the poor, who in turn become less willing to support this kind of public spending.
\end{abstract}

\section{Keywords}

education, inequality, individual preferences, OECD countries, political economy

\section{Introduction}

The issue of skill formation occupies a prominent place in the political economy of redistribution (Estévez-Abe et al., 200 ; Iversen, 2005; Iversen and Soskice, 2001, 2009). Furthermore, a number of recent studies have significantly expanded our knowledge about the dynamics of education politics and policies at the aggregate country level (Ansell, 2008, 2010; Busemeyer, 2007, 2009; Jensen, 2011;
Schmidt, 2007). However, the pertinent literature has, for the most part, largely ignored the study of

\section{Corresponding author:}

Marius R. Busemeyer, Department of Politics and Public

Administration, University of Konstanz, PO Box 79, D-78457

Konstanz, Germany

Email: marius.busemeyer@uni-konstanz.de 
the micro-foundations of education policy in terms of individual policy preferences and their interaction with macro variables (partial exceptions are Ansell, 2010; Busemeyer et al., 2009, 2011; Kitschelt and Rehm, 2006). Admittedly, comparative welfare state research has produced important insights into the micro- and macro-level determinants of social policy preferences (Arts and Gelissen, 2001; Blekesaune and Quadagno, 2003; Corneo and Grüner, 2002; Goerres and Tepe, 2010; Hasenfeld and Rafferty, 1989; Jaeger, 2009; Lynch and Myrskylä, 2009; Scheve and Stasavage, 2006), but has not studied individual preferences on education policies. Scholarship in the sociology of education is more concerned with studying the determinants of actual educational choices and attainment (Becker and Hecken, 2009; Breen and Goldthorpe, 1997; Breen and Jonsson, 2005; Breen et al., 2009) rather than the preferences of individuals on policies as such. Thus, simply from an empirical point of view, this paper addresses an important research gap by studying the micro- and macro-level determinants of individual preferences on public investments in education.

From a more theoretical perspective, the present paper contributes to ongoing debates in the political economy of redistribution. Starting with the seminal contribution of Meltzer and Richard (1981), scholarship in political economy has deduced individual preferences for redistribution from the individual's position in the distribution of incomes and skills. Work by Boix $(1997,1998)$ and Ansell $(2008,2010)$ applies this modelling framework to the study of education. However, as this paper shows, the impact of the individual income position on preferences strongly depends on the interaction between the micro level and the institutional context at the macro level. Because the redistributive implications of investments in education are much less clear-cut than other public policies, preferences for education spending are a well-suited example to use to tease out the impact of macro contexts on the micro-level dynamics of preference formation.

The central research question of this paper is thus to analyse how institutional contexts shape the micro-level association between income and support for education spending. More specifically, I argue that individual preferences are influenced by two aspects of the macro-level context: first, the level of socio-economic inequality in the political economy and, second, the level of educational inequality. Both dimensions of inequality have a different and distinct impact on the role of income as a determinant of spending preferences at the micro level. In line with the expectations of the Meltzer-Richard model, higher levels of socio-economic inequality are associated with an increase in the general support for education spending, as well as a more pronounced negative effect of income on preferences at the micro level, that is the rich/poor are more likely to oppose/ support spending increases. By contrast, high levels of educational inequality mitigate the negative impact of income on support for spending. High levels of educational inequality imply more restricted access to higher levels of education for people with lowincome backgrounds. Hence, further public investments in education are of more benefit to the rich than the poor. Therefore, the rich/poor are more likely to support/oppose spending increases when levels of educational inequality are high.

The remainder of the paper is structured as follows: the second section provides a brief literature review, followed by a more detailed account of the theoretical framework of the paper. The fourth section puts the previously developed hypotheses to an empirical test, relying on survey data for a large number of Organisation for Economic Co-operation and Development (OECD) countries. The last section discusses the findings in light of the literature and provides a conclusion.

\section{Literature review}

Our knowledge of the institutional and partisan factors influencing redistributive politics has expanded significantly in the last years. The model by Meltzer and Richard (1981) is a popular point of departure in the pertinent political economy literature as it provides a clear and compelling thesis: redistribution is expected to increase with rising levels of inequality because, at least in industrial democracies, the poor majority can vote to tax the rich minority. A lot of recent work has focused on explaining the relationship between redistribution and inequality on the 
macro level, which seems to run counter to the expectations of the Meltzer-Richard model (Bradley et al., 2003; Iversen and Soskice, 2006, 2009; Moene and Wallerstein, 2001, 2003).

In addition to work on the macro-level determinants of inequality and redistribution, scholars have become more interested in exploring the micro-level foundations of redistributive preferences. Again, the Meltzer-Richard (1981) model provides clear expectations: demand for redistribution is a function of the individual's distance to the mean income. Poor people with below-average incomes demand high levels of redistribution and taxation. This demand decreases as income increases and becomes zero for the person with a mean income and everybody with above-average incomes. The share of the population supporting positive levels of redistribution then strongly depends on the level of inequality, that is the difference between the mean and the median income. Empirically, a large body of literature studying the determinants of individual social policy preferences has confirmed the importance of individual income (despite the negative association between redistribution and inequality at the macro level). Self-interest, shaped by the individual's position in the economy, the labour market and the transfer classes of the welfare state, as well as skill portfolio, strongly affects preferences for different social policies (Busemeyer et al., 2009; Corneo and Grüner, 2002; Cusack et al., 2006; Iversen and Soskice, 2001; Hasenfeld and Rafferty, 1989; Rehm, 2009). Moene and Wallerstein $(2001,2003)$ show that preferences for redistribution can actually increase with rising income: when certain kinds of income-related social policies provide a form of insurance against income losses, the demand for this insurance increases with income.

As documented here, there is by now a welldeveloped scholarship on the political economy of redistribution and its implications at the micro level in general. There are, however, only a few studies that are concerned with the study of education from the perspective of comparative political economy. Again, most of these studies are concerned with the macro level, for example the relationship between education and welfare state institutions (EstevezAbe et al., 2001; Iversen and Stephens, 2008) or the determinants of education spending (Busemeyer, 2007, 2009; Jensen, 2011; Schmidt, 2007).

Building on the contributions of Boix (1998, 1997), Ben Ansell $(2008,2010)$ has developed the most elaborate model on the formation of individual preferences over different kinds of higher education so far. Following the logic of the Meltzer-Richard model (1981), investments in (higher) education are evaluated with regard to their distributive consequences for the different income strata in a given political economy. Consequently, preferences are derived from the individual's position on the income scale: according to Ansell, when levels of general enrolment in higher education are low (that is, access to higher education is restricted to the wealthy elite), members of the lowincome classes enter a formal or informal 'endsagainst-the-middle' coalition with the rich against the middle classes, because both oppose the expansion of public subsidies to higher education (Ansell, 2008: 198) - the rich because they want to maintain an elitist system and the poor because they do not want to subsidize a type of education with limited benefits for them. ${ }^{1}$ However, when levels of enrolment in higher education increase, more people from the lowerincome classes get access to higher education and therefore come to support the expansion and public subsidization of higher education. Based on this micro model of preference formation, Ansell then proceeds to demonstrate how the partisan preferences of leftist parties as proponents of the economic interests of the lower-income classes change depending on the level of enrolment in higher education from opposing public subsidies for higher education to supporting them (Ansell, 2008: 205-8).

Ansell's model is an important first step in developing a more comprehensive theory on the political economy of education, but for the purpose of the present paper it has several shortcomings: first, Ansell is concerned with explaining preferences on different kinds of higher education, whereas I am concerned with preferences on education more generally. A broadening of the analytical perspective beyond higher education is necessary, because lower levels of enrolment in higher education might be not only a consequence of restrictions of access. For example, individuals from low-income classes might support increasing public investments on vocational 
education in countries where these alternatives are available (Busemeyer et al., 2011; see also Ansell, 2010, Chapter 4). Second, Ansell's model hints at the importance of macro-level variables such as the general level of enrolment for the formation of preferences, but he is more concerned with explaining the impact of educational expansion on the changing partisan politics of higher education over time, essentially assuming that his micro model of preference formation works similarly in different countries, although the impact of opening access to higher education on micro-level preferences is considered as an extension to the main model (Ansell, 2008: 203-4). In contrast, the present paper postulates that differences across country contexts fundamentally shape the redistributive politics over educational investments. Also, Ansell's model captures just one particular aspect of educational inequalities - the level of enrolment in higher education - whereas I adopt a broader perspective on the role of the stratification of education systems and look at the distinct impact of economic inequalities as well.

\section{Theoretical framework: determinants of education policy preferences}

The following section introduces a theoretical framework in order to explain individual policy preferences on public education spending. The first subsection discusses the contradictory expectations on the impact of income on redistributive preferences in the case of education, and then proceeds to resolve these ambiguities by clarifying how the macro-institutional context shapes the importance of income as a determinant of preferences over education spending. In the second subsection, I present auxiliary hypotheses on determinants of preferences besides income.

\section{Income and institutional context as determinants of preferences}

The redistributive consequences of general investments in education are much less clear-cut than in the case of redistributive social policies or higher education, as discussed by Ansell. This leads to ambiguous expectations and predictions with regard to the impact of income on individual preferences. On the one hand, it could be argued that the expansion of public education in the long run contributes to mitigating economic inequalities, in particular when the alternative is to resort to expensive private education. Therefore, the less well-off have an incentive to support increases in public spending on education to improve the conditions for upward social mobility for their offspring. In contrast, the wealthy might oppose such efforts, because they would have to pay for these subsidies in the form of higher taxes and because their relatively superior class position would be threatened by the enhanced levels of social mobility (Bernasconi and Profeta, 2007).

On the other hand, investments in education have only a very indirect impact on the inter- and intragenerational redistribution of resources. Hence, the lower-income classes might care more about expanding other social policies with more immediate redistributive consequences instead of education. The wealthy, in contrast, could actually support the expansion of public subsidies to education, because, as a consequence of lingering class biases about access to education, they expect to benefit more from it than from other social policies (Fernandez and Rogerson, 1995). This redistribution from the poor to the rich is expected to be strongest in the case of public subsidies to higher education, as argued by Ansell (2008). In sum, therefore, the effects of income on education preferences are contradictory (Levy, 2005) and could cancel each other out in the aggregate, so that the individual's income position as such is not a significant determinant of preferences for education spending.

However, as is argued in the following, when the interaction between the micro-level and macro-level contexts are taken into account, the individual's position on the income scale matters. The macro context impacts on and shapes the process of preference formation at the micro level because it influences the relative pay-off of public investments in education for different income classes. I am going to argue how and why individual support for increases in education spending depends on two macro factors: first, the general level of socio-economic inequality and, 
second, the more specific level of educational inequality. Thus, both socio-economic and educational inequality are expected to jointly shape levels of individual support for increases in education spending, although these two dimensions are empirically distinct from each other (see the section below for empirical data).

Coming first to the impact of socio-economic inequality, it is important to distinguish between the effect on the overall level of support and the effect on the impact of income on the level of support. The first is the direct effect of the macro context on individual support, whereas the latter captures the interaction effect between the micro and the macro level.

Following the basic model of Meltzer and Richard (1981) and assuming the typical right-skewed distribution of income, an increase in socio-economic inequality without changing the level of the average (mean) income is expected to result in an increase of the overall support for public spending. This is because such an increase in inequality leads to a larger share of the population with below-mean incomes, as the relative distance between the individual with median income and the average (mean) income increases. Although public investments in education might be regarded as less redistributive than other kinds of social policies (Ansell, 2008; Jensen, 2011), they are still redistributive to the extent that the rich are forced to pay for the education of the less well-off in the form of taxes. Thus, the first hypothesis to be tested is that increases in the levels of socio-economic inequality are associated with higher support for increases in public education spending.

What is the impact of socio-economic inequality on the effect of income on support? Although this issue is not discussed explicitly, the MeltzerRichard framework is useful for developing concrete hypotheses. The basic insight of this model is that the rich are less likely to support increases in public spending than the poor, that is the effect of increases in individual income on support for public spending at the micro level is negative. Following up on this logic, higher levels of socio-economic inequality are expected to enhance the conflict over redistribution based on income. In egalitarian countries, the income positions of the rich and the poor relative to the median voter are closer to each other. Therefore, the role of income as a factor determining conflicts over redistribution is diminished. In contrast, the relative positions of the rich and the poor are further away from each other in inegalitarian country contexts. Hence, the effect of income on individual preferences is expected to be more pronounced. The poor/rich in inegalitarian countries are believed to more intensely support/oppose increases in public spending because their relative position is further away from the median voter. In sum, increases in the level of socio-economic inequality are expected to enhance the negative effect of income, that is the cross-level interaction between income and socio-economic inequality is hypothesized to be negative.

The hypotheses developed so far are well established in the literature. The new contribution of this paper is to argue that other dimensions of inequality, such as educational inequality, matter as well. Most importantly, I will argue in the following that the effect of educational inequality on the political economy of education spending preferences at the micro level is quite different from the effect of socioeconomic inequality.

What is educational inequality and how is it related to socio-economic inequality? Whereas socio-economic inequality captures the extent of existing inequalities on the labour market and in the distribution of wealth and income, the concept of educational inequality relates to the degree of stratification entailed in the institutional set-up of the education system. To what extent educational stratification is related to socio-economic inequality is not well understood. Empirically, the two dimensions are not related at all (see below). Research in educational sociology has shown that features such as the degree of tracking in the secondary school system, the mobility and permeability between vocational and higher education, as well as the availability of early childhood education are important factors determining educational stratification (see, for example, Allmendinger, 1989; Breen et al., 2009; Schlicht et al., 2010).

In the following, I will develop hypotheses on the impact of educational inequality. I start again with a discussion of the direct effect of educational inequality 
on overall levels of support for increases in education spending. Here, the expectations are not as clear-cut as in the case of socio-economic inequality. On the one hand it could be argued that the overall demand for public education investments is higher in education systems with high levels of inequality because there is a higher number of individuals who face barriers in getting access to education. In the logic of Meltzer and Richard (1981), higher levels of educational inequality would thus lead to a higher demand for investments in education, as these would probably result in a lowering of barriers of access. As is argued by Iversen and Stephens (2008) and Busemeyer (2009), left-wing parties in government have increased public spending on education and higher education in order to open up access for lowincome families, for example by creating more university places. On the other hand, high levels of educational inequality could also delegitimize further investments in education because these might not lead to an expansion of access and instead benefit the education insiders. Those excluded from access to higher levels of education (the poor) could then be more likely to oppose further spending on education and demand more direct forms of redistributive spending. In sum, it is not possible to formulate clear expectations with regard to the direct effect of educational inequality on support for spending increases, and thus this effect is expected to be weak.

In contrast, clear expectations can be developed in the case of the effect of educational inequality on the effect of income on support for spending (cross-level interaction). Levels of educational inequality indicate the severity of class bias regarding access to education, that is the extent to which individuals with a weak socio-economic background can get access to higher levels of education. This factor is strongly related to the structure of secondary education. Barriers of access are usually higher in countries with early tracking of students into separate vocational and academic paths (Pfeffer, 2008). Thus, even though individuals might not necessarily be aware of the real extent of educational inequality, they usually have a good understanding of the structure of secondary education systems.

In countries with low levels of educational inequality, barriers of access are lower than in countries with high levels of inequality. Building on
Ansell (2008), it could then be argued that poor people will be more opposed to increasing public spending on education when levels of educational inequality are high. On the other hand, rich people might be more willing to support spending increases in the presence of high educational inequality, because the existing barriers to access ensure that the well-off will benefit disproportionally from these investments. Thus, the extent of educational inequalities determines whether increased public spending will be of more benefit to those outside education (the poor) or those inside education (the rich). An increase in educational inequality is expected to increase the support for more spending among the rich, whereas it will lower the support among the poor. The impact of educational inequality on the income effect is thus hypothesized to be the opposite of the impact of socio-economic inequality. Instead of aggravating the income effect, higher levels of educational inequality are expected to turn the negative income effect around, because the rich/poor are thought to be more likely to support/ oppose spending (positive interaction effect).

The core hypotheses to be tested can be summarized as such:

Hypothesis 1.1: Increases in socio-economic inequality are expected to be associated with higher levels of support for public education spending (direct effect).

Hypothesis 1.2: Increases in socio-economic inequality are expected to be associated negatively with the income effect at the micro level (cross-level interaction).

Hypothesis 2.1: Increases in educational inequality are not expected to be associated significantly with general levels of support for increases in public education spending.

Hypothesis 2.2: Increases in educational inequality are expected to be associated positively with the income effect at the micro level (cross-level interaction).

\section{Auxiliary hypotheses and control variables}

Besides the individual position on the income scale, other factors are expected to determine preferences 


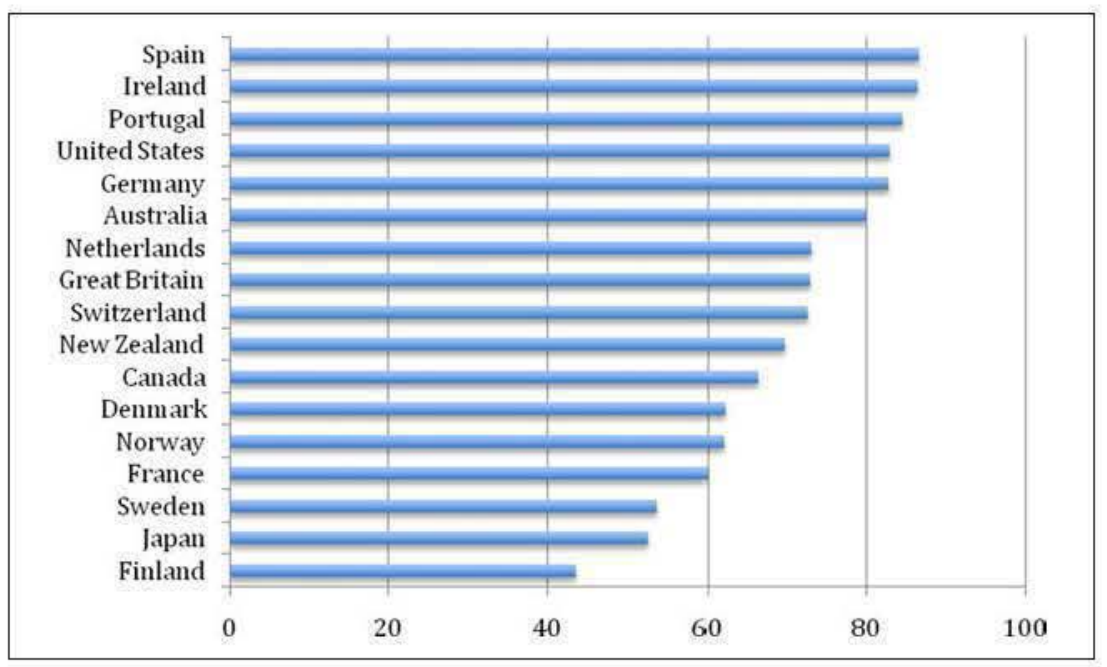

Figure I. Percentage share of respondents being in favour of 'more' or 'much more' government spending on education, ISSP Role of Government IV, 2006.

for education spending at the micro level. Given the dearth of empirical studies on this, the present paper also wants to shed light on the relevant micro- and macro-level determinants of preferences. In the literature on welfare state attitudes cited above, it has been shown that individuals' support for different welfare state programmes at least in part hinges on whether they believe they will become beneficiaries of this programme in the future (Hasenfeld and Rafferty, 1989). In the case of education, this kind of self-interest-based explanation needs to be modified, because only a subset of the population (for example the young or teachers) are direct beneficiaries of increased public provision of educational services despite the fact that increases in spending are supported by large majorities in many OECD countries (Figure 1). Self-interest-based explanations of preferences need to be based on the more indirect benefits/ costs of increased investments in education, for example the impact of educational investments on the general productivity of the economy or the consequences of educational investments for the distribution of resources in the subsequent generation. Based on this 'enlightened' notion of self-interest-based explanations, several hypotheses can be developed.

First of all, while the distributive consequences of public investments in education might be less clearcut in the case of income, they are obvious in the case of age. Young people of all income classes benefit from public investments in education, whereas older people do not (or, at best, indirectly, because investments in education enhance the economic productivity of the society as a whole) (Busemeyer et al., 2009; Cattaneo and Wolter, 2007; Gradstein and Kaganovich, 2004). Therefore, I expect a strong relationship between the individuals' position in the life cycle and preferences for education spending.

Second, in a related manner, individuals with children are expected to be more supportive of increases in public education spending as this benefits them and their children directly, for example by reducing the private share in the financing of their children's education. Women have been found to be more supportive of redistribution than men (Svallfors, 1997: 292); therefore, I also look at the impact of gender on preferences for education spending.

Third, educational background is expected to be a major determinant of education policy preferences. Since the work of Boudon (1974), scholarship in the sociology of education has repeatedly shown how educational choices and attainment are shaped by class differentials (Breen and Goldthorpe, 1997), in which non-pecuniary resources such as social and cultural capital are at least as important as monetary resources. Simply as a result of their larger stock of human capital, highly educated individuals have an 
informational advantage over less educated individuals in navigating the obstacles of the education system. Owing to the class bias regarding access to education, their children are more likely to experience higher levels of education. Hence, I expect a positive association between individual educational background and support for increases in public spending on education.

Fourth, labour market position and status matter as well. Individuals in education (students, apprentices, trainees. ..) can be expected to be more supportive of increased spending on education. It is less clear whether those currently unemployed or in precarious employment support higher education spending. On the one hand, investments in education might improve their chances of re-employment. On the other hand, labour market outsiders might prefer direct forms of redistribution via social transfers to education.

In addition to micro-level determinants, I include one additional macro variable: the current level of public education spending. Following Wlezien's (1995) 'the public as thermostat' approach, public support for further increases in spending should be lower when education spending is high and vice versa, which essentially assumes that voters have some kind of preferred average level of spending and disapprove of over- and underinvestment.

I refrain from including partisan ideology as a determinant of preferences at the micro level. Other studies (Busemeyer et al., 2011) have shown that individuals identifying with the left are more likely to support increases in education spending. However, Idema (2010) rightly points out that self-identification with partisan ideology is not purely exogenous, but also determined by the other micro-level variables (for example income, education and gender) included in the model. Because partisan ideology does not feature prominently in the explanatory model, I decided to not include it in the models. ${ }^{2}$

\section{Empirical analysis}

\section{Data}

To keep in line with conventions of scholarship in the field and to make the results comparable with other work, I rely on data from the 2006 wave of the International Social Survey Programme (ISSP) 'Role of Government IV'. In this survey, respondents were asked the following question:

Listed below are various areas of government spending. Please show whether you would like to see more or less government spending in each area. Remember that if you say 'much more', it might require a tax increase to pay for it.

'Education' is listed as one of several areas where government spending should be increased. The answers of respondents to these questions are coded on a scale from 1 (spend much more) to 5 (spend much less). To improve readability, this scale is then reduced to a binary indicator (spend more or much more equals 1 , spend the same, less or much less equals 0 ).

This question seems to be reasonably well suited to measuring preferences for public subsidization of education, but it has several weaknesses that should be kept in mind in the following analysis. For one, although the wording of the question mentions the fact that higher spending has to be paid for via tax increases, the framing of the question and the set-up of the survey in general do not model very strong budget constraints on spending decisions. Therefore, it might well be that preferences for spending increases are overstated. Furthermore, particularly in the case of education, it would be important to ask about the relative contribution of public and private sources to funding. The way the question is framed does not allow for a distinction to be made between the individuals' willingness to increase (public) spending on education as such or the relative share of public vis-à-vis private sources.

Finally, a major disadvantage of this measure is that it does not distinguish between spending for different kinds of education, such as higher education and vocational training. In line with Ansell, it could be expected that the hypothesized effects of educational inequality on the income effect should be even more pronounced in the case of spending preferences for higher education, whereas they should be attenuated in the case of vocational education. Unfortunately, the ISSP data do not allow for this 
kind of differentiation. Ansell (2010, Chapter 5) uses a second ISSP survey question in addition to the one used in this paper. Here, individuals are asked whether the government should provide financial support to university students from low-income families. This question, although more focused on higher education, is less useful for answering the research question of this paper because it blends out the question of access. In a different paper, we use data from a 2004 Eurobarometer survey that contains a question about which kind of education (academic, vocational) respondents would recommend to school leavers (Busemeyer and Jensen, 2012). The downside of using this survey is that it does not contain any data on income and therefore cannot be used in the present context. Also, 'recommendations' are certainly not the same as spending preferences. In yet another paper (Busemeyer et al., 2011), we rely on a survey from Switzerland that provides more differentiated data on spending preferences. However, this survey obviously does not allow for a control to be used for the impact of different country contexts. In sum, the ISSP data set provides the best data that are available.

The countries covered by the survey and included in this analysis are Australia, Canada, Denmark, Finland, France, Germany, Great Britain, Ireland, Japan, New Zealand, the Netherlands, Norway, Portugal, Spain, Sweden, Switzerland and the United States. I restrict the sample to western OECD countries because the theoretical approaches discussed above are based on the study of mature welfare states in advanced democracies.

Figure 1 presents some descriptive statistics on the variation of education policy preferences in the countries under observation. More specifically, Figure 1 depicts the share of the respondents who answered 'spend more' or 'spend much more' on the question about whether government spending on education should be increased. As can be seen, there is a large amount of variation in this variable, with the highest ranking country (Spain, 86.5\%) scoring almost twice as much as Finland (43.6\%), the country at the lower end. Interestingly, countries such as Finland, Norway, Denmark and Sweden, which are characterized by the highest levels of education spending in an international context, are to be found at the bottom of the ranking. In contrast, increasing spending on education is very popular in countries suffering from underinvestment in education (such as the United States with regard to primary and secondary education and Germany for higher education). Also, the Mediterranean countries (Spain and Portugal) are close to or at the very top of the ranking. Despite these patterns, no clear clustering of countries is discernible.

The independent variables at the micro level are operationalized as follows: in the ISSP data, income is given as absolute amounts in national currency units. In order to create a common measure of income, I calculated income deciles for the individual countries and then merged these into a joint variable. The position in the life cycle is captured by a dummy variable for retired persons. As an alternative, one could simply use the respondent's age. ${ }^{3}$ Education is measured as the number of years spent in education. This approach is preferable to using specific educational degrees as ambiguities about the mapping of countryspecific degrees to internationally comparable classifications remain. Having children is captured by a dummy variable $(1=$ yes, $0=$ no) and based on a question about household composition (HHCYCLE). Gender is indicated by a dummy variable as well (female =1). Labour market status is measured in two categorical variables: student, school, vocational training, apprentice or trainee; and 'outsider', which equals ' 1 ', for those who are unemployed, employed less than part time or employed part time and feeling that 'people like me have no say in what government does' (based on Q11). ${ }^{4}$

With regard to macro-level variables, the two most important independent variables are measures of educational and socio-economic inequality. In fact, as is shown in Figure 2, the cross-national association between the levels of socio-economic and educational inequality is not very strong. The bivariate correlation in the sample is 0.003 . On the $x$-axis, I plot levels of socio-economic inequality (Gini index) for the year 2005, as provided in the Standardized World Income Inequality Database (Solt, 2009). The Gini index is a measure of the equality of the distribution of income across households. Higher values indicate higher levels of inequality and vice versa. The $y$-axis is a measure of educational inequality 


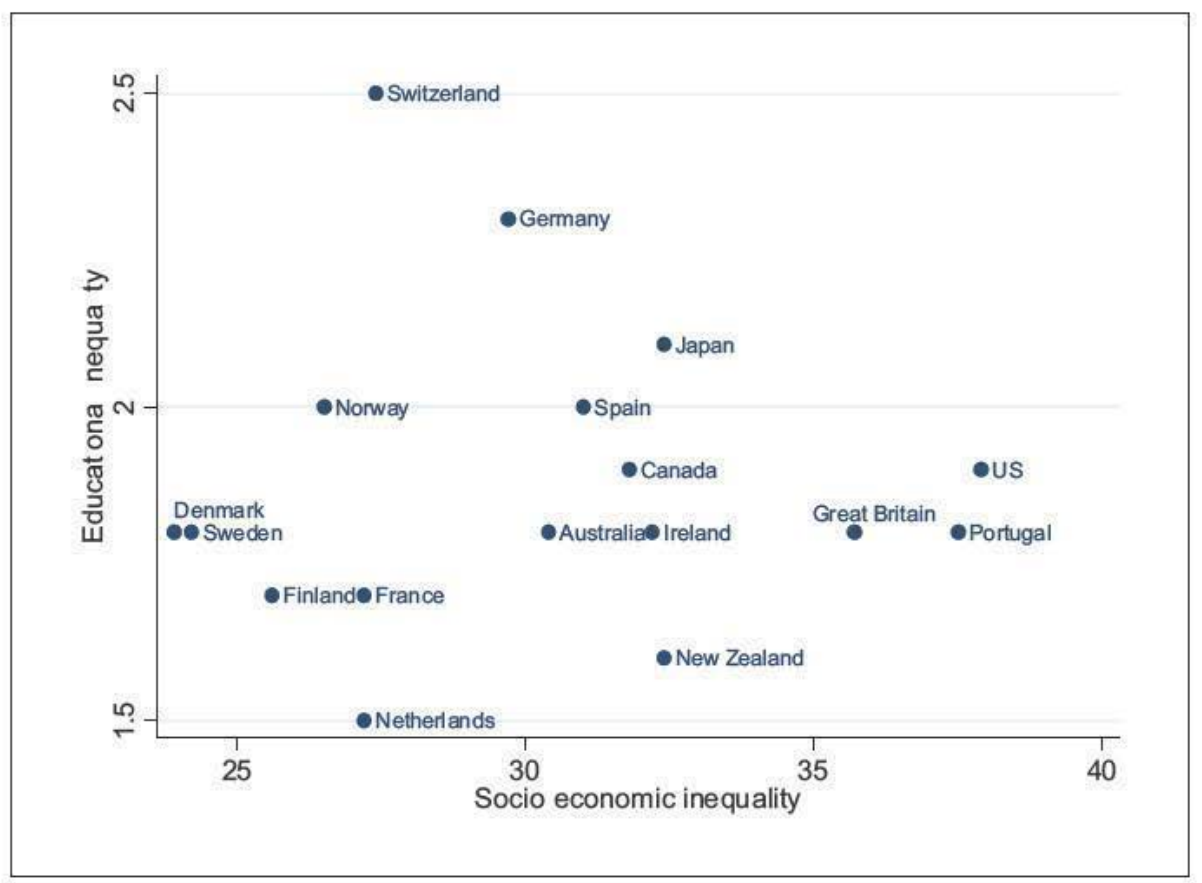

Figure 2. Socio-economic and educational inequality.

Sources: Socio-economic Inequality: Ginl Index (2005), Solt, 2009; Educational Inequality. odds ratio of expecting to complete higher education between 15-year-old student with high and low soclo-economlc status, OECD, 2007: 87.

provided by the OECD (OECD, 2007: 87) based on data from the PISA studies. It captures the difference (odds ratio) in the expected completion of higher education between a student with a low socioeconomic background and one with a strong socioeconomic background. Higher values in this measure indicate a larger advantage for students from strong socio-economic backgrounds, that is a higher level of educational inequality. As can be seen from Figure 2, countries such as Germany and Switzerland exhibit high levels of educational inequalities (see also Pfeffer, 2008), but only moderate levels of inequality. Other countries, for example the United States and Portugal, combine high levels of socioeconomic inequality with moderate levels of educational stratification. The Scandinavian countries, as could be expected, exhibit both low levels of educational and socio-economic inequality. As an alternative to the OECD measure, ${ }^{5}$ I use Pfeffer's (2008) indicator of educational mobility based on a large sample of more than 38,000 cases and using data from the OECD International Adult Literacy Survey. In this measure, higher values indicate higher levels of educational mobility, that is, a lower degree of stratification. The indicator ranges from -0.27 (low educational mobility in Germany) to 0.24 (high educational mobility in Finland). To make it comparable with the OECD measure, the direction of the scale was reversed. The Pfeffer measure is available for only 11 out of the 17 countries covered by the ISSP survey. As a second alternative to the OECD measure, I simply use the current level of net enrolment in tertiary education (OECD, 2007: 345). This is a very imperfect measure of educational inequality. Nevertheless, higher levels of enrolment indicate broader access to higher education, that is less educational inequality. Because this indicator points in the opposite direction of the OECD measure, the sign of the coefficient on the interaction is expected to be negative. Moreover, I include 2005 levels of public education spending as percentage of GDP from the latest edition of the OECD factbook. 


\section{Methods}

With regard to methods, I use two alternatives. First, I employ multilevel logit analyses with cross-level interactions. Because of the high share of positive responses in the ISSP question, it seems advisable to transform the original five-point scale into a binarydependent variable, indicating support or no support for more spending (see above). The models are estimated as random effects models with the country as the grouping variable. Cross-level interactions are included together with the constituent terms on the micro and macro levels. The advantage of this procedure is that all the different kinds of effects can be considered jointly in a single multilevel model. The downside is that it is implicitly assumed that all the variation on the second level (the macro level) is captured by the included macro variables (Lewis and Linzer, 2005: 347). An alternative would be to include country dummies, but this leads to the exclusion of the macro variables, which are of interest from a substantive perspective. Nevertheless, I also present a model with country dummies to show the robustness of the findings with regard to the crosslevel interactions.

Second, the effects of macro-level variables on micro-level associations are further probed by means of two-step hierarchical estimation (Achen, 2005; Duch and Stevenson, 2005; Huber et al., 2005; Lewis and Linzer, 2005). In the first step of this procedure, separate regressions are run for the individual units (countries). In the second step, estimates from the first step are used as dependent variables in weighted least squares regressions, using robust standard errors and inverse standard errors of the coefficients from the first stage as weights. According to Huber et al. (2005: 366), the two-step estimation is preferred "when there is a binary dependent variable in the first stage, and when the number of second-level units - countries in our case - is relatively small'. The results of the first stage can also be used to calculate changes in the predicted probability of supporting increases in education spending resulting from a change in the income position (from one country-specific standard deviation below the mean to one standard deviation above the mean).
The application of multilevel modelling techniques, however, cannot solve the fundamental problem that the number of units (countries) at the macro level is small. As a consequence, the number of control variables at this level were kept to a minimum.

\section{Findings}

Table 1 presents the results of the analysis of preferences for education spending. First, I discuss the micro-level determinants of support for education spending (Model 1). The most intriguing finding is that the individual position in the income distribution does not have an impact on preferences on education spending. The coefficient estimate for the income variable is far from reaching conventional levels of statistical significance despite the large sample. Instead of income, other factors determine individual preferences for education spending. The strongest and most robust effect is the impact of educational background on preferences. The longer an individual stayed in school or university, the higher the support for increased education spending. In the same vein, those still enjoying the benefits of education (students, apprentices, trainees. . .) are more supportive of further increases in government spending. Another important determinant of support for increases in public spending is whether the respondent has children living in her household. These findings are reminiscent of the self-interest thesis of transfer classes in the welfare state literature: parents are more supportive of increasing public funding for education than childless individuals.

The remaining independent variables do not have a strong impact on support for public education spending. Gender and age do not matter, although, similar to the effect of income, the pooled estimate might mirror significant cross-country variation (Busemeyer et al., 2009). ${ }^{6}$ Labour market outsiders (the unemployed and those with temporary or unstable employment) do not care about increases in education spending. Although further investment in their skills might benefit their future prospects on the labour market, investments in initial education and training provide a less direct support for them than transfers or unemployment benefits. 
Table I. Determinants of preferences on education spending

Dependent variable

More or much more public spending on education $=1$

\section{Micro level}

Income

Gender (female = I)

Same or less public spending $=0$

Education

Having children

Retired

Labour market outsider

Student, apprentice, etc.

$\begin{array}{cc}-0.00616 & -0.248 * * * \\ (0.00991) & (0.0874) \\ 0.0495 & 0.0567 \\ (0.0370) & (0.0371) \\ 0.0250 * * * & 0.0244 * * * \\ (0.00501) & (0.00502) \\ 0.335 * * * & 0.335 * * * \\ (0.0395) & (0.0396) \\ 0.0263 & 0.0301 \\ (0.0503) & (0.0503) \\ 0.0633 & 0.0633 \\ (0.0634) & (0.0633) \\ 0.375 * * * & 0.379 * * * \\ (0.130) & (0.131)\end{array}$

$0.279 * * *$
$(0.0681)$
0.0559
$(0.0370)$
$0.0243 * * *$
$(0.00500)$
$0.330 * * *$
$(0.0396)$
0.0394
$(0.0504)$
0.0691
$(0.0636)$
$0.420 * * *$
$(0.132)$

\subsection{8}

$(0.110)$

$0.0623 *$

$(0.0371)$

$0.0238 * \% *$

(0.00501)

$0.329 \% *$

$(0.0396)$

0.0424

$(0.0504)$

0.0689

$(0.0635)$

$0.422 * * *$

(0.132)

$\begin{array}{cc}-0.378 * * & -0.186 \\ (0.167) & (0.171) \\ & 0.110^{* * *} \\ & (0.0355)\end{array}$

$-0.125$

(0.607)

Educational inequality

(Pfeffer measure)

Net enrolment in tertiary

education

\section{Cross-level interactions}

Income * socio-economic inequality

Income * educational

inequality

$0.134 * *$

$-0.166$

$(0.173)$

0.112 ***

(0.0353)

0.0107

(0.535)

$0.426 * * *$
$(0.0761)$
-0.00235
$(0.0474)$
$0.0253 * * *$
$(0.00665)$
$0.300 * * *$
$(0.0506)$
0.0887
$(0.0659)$
$0.146 *$
$(0.0802)$
$0.530 * * *$
$(0.150)$

$0.232 * * *$
$(0.0717)$
$0.0725 *$
$(0.0381)$
$0.0229 * * *$
$(0.00507)$
$0.322 * * *$
$(0.0409)$
0.0411
$(0.0518)$
0.0629
$(0.0650)$
$0.436 * * *$
$(0.133)$

0.0316

(0.110)

0.0618 *

$(0.0371)$

$0.0241 * * *$

(0.00502)

$0.330^{* * * * *}$

(0.0396)

0.0409

(0.0505)

0.0672

$(0.0636)$

$0.421 * * *$

$(0.132)$

$-0.136$

(0.216)

$0.142 * * *$

$-0.626 * * *$

$-0.489 * * *$

(0.107)

(0.0446)

$(0.0371)$

$0.0927 * * *$

$(0.0220)$

$1.434 *$

(0.738)

$-0.00944 * * *$

$(0.00222)$

$(0.0480)$

$-0.00954 * * *$

(0.00223)

$-0.0133 *$

(0.00250)

$0.136 * * *$

(0.0484)

$-0.0120$

$(0.00881)$

$-0.00277$

$-0.00943 * * *$

$(0.00223)$

$0.137 * * *$

$(0.0485)$ 
Table I. (Continued)

\begin{tabular}{|c|c|c|c|c|c|c|c|}
\hline \multirow[b]{2}{*}{ Dependent variable } & ( 1 ) & (2) & (3) & (4) & (5) & (6) & (7) \\
\hline & \multicolumn{7}{|c|}{$\begin{array}{l}\text { More or much more public spending on education }=1 \\
\text { Same or less public spending }=0\end{array}$} \\
\hline $\begin{array}{l}\text { Income * educational } \\
\text { inequality (Pfeffer measure) }\end{array}$ & & & & & $\begin{array}{r}0.170 * * \\
(0.0850)\end{array}$ & & \\
\hline $\begin{array}{l}\text { Income * enrolment in } \\
\text { tertiary education }\end{array}$ & & & & & & $\begin{array}{l}-0.00450 * * * \\
(0.00122)\end{array}$ & \\
\hline Constant & $\begin{array}{l}0.474 * * * \\
(0.175)\end{array}$ & $\begin{array}{l}2.600 * \\
(1.555)\end{array}$ & $\begin{array}{l}-1.908 \\
(1.699)\end{array}$ & $\begin{array}{l}-2.111 \\
(2.142)\end{array}$ & $\begin{array}{l}-3.135 \\
(2.124)\end{array}$ & $\begin{array}{c}1.339 \\
(1.009)\end{array}$ & $\begin{array}{l}3.020 * * * \\
(0.234)\end{array}$ \\
\hline \multicolumn{8}{|l|}{ Variance components } \\
\hline $\begin{array}{l}\text { Level-2 intercept Standard } \\
\text { deviation }\end{array}$ & $\begin{array}{c}0.6542 \\
(0.1138)\end{array}$ & $\begin{array}{l}0.5632 \\
\mathrm{~m}(0.0985)\end{array}$ & $\begin{array}{l}0.4941 \\
(0.0869)\end{array}$ & $\begin{array}{l}0.4861 \\
(0.0856)\end{array}$ & $\begin{array}{c}0.2622 \\
(0.0615)\end{array}$ & $\begin{array}{c}0.2457 \\
(0.0493)\end{array}$ & \\
\hline $\begin{array}{l}\text { Intraclass correlations } \\
\text { (Rho) }\end{array}$ & $\begin{array}{c}0.1151 \\
(0.0354)\end{array}$ & $\begin{array}{c}0.0879 \\
(0.028 I)\end{array}$ & $\begin{array}{c}0.0691 \\
(0.0226)\end{array}$ & $\begin{array}{c}0.0670 \\
(0.0220)\end{array}$ & $\begin{array}{c}0.0205 \\
(0.0094)\end{array}$ & $\begin{array}{c}0.0180 \\
(0.0071)\end{array}$ & \\
\hline Log likelihood & $-97 \mid 2.5077$ & -9706.1084 & -9699.1245 & -9694.8135 & -5793.184 & -9160.1729 & -9654.3161 \\
\hline Country dummies & No & No & No & No & No & No & Yes \\
\hline Observations & 17,337 & 17,337 & 17,337 & 17,337 & 9,959 & 16,580 & 17,337 \\
\hline Number of countries & 17 & 17 & 17 & 17 & 11 & 16 & 17 \\
\hline
\end{tabular}

Standard errors in parentheses.

$*_{p}<0.1$, *** $p<0.05$, ***kp $<0.01$. 


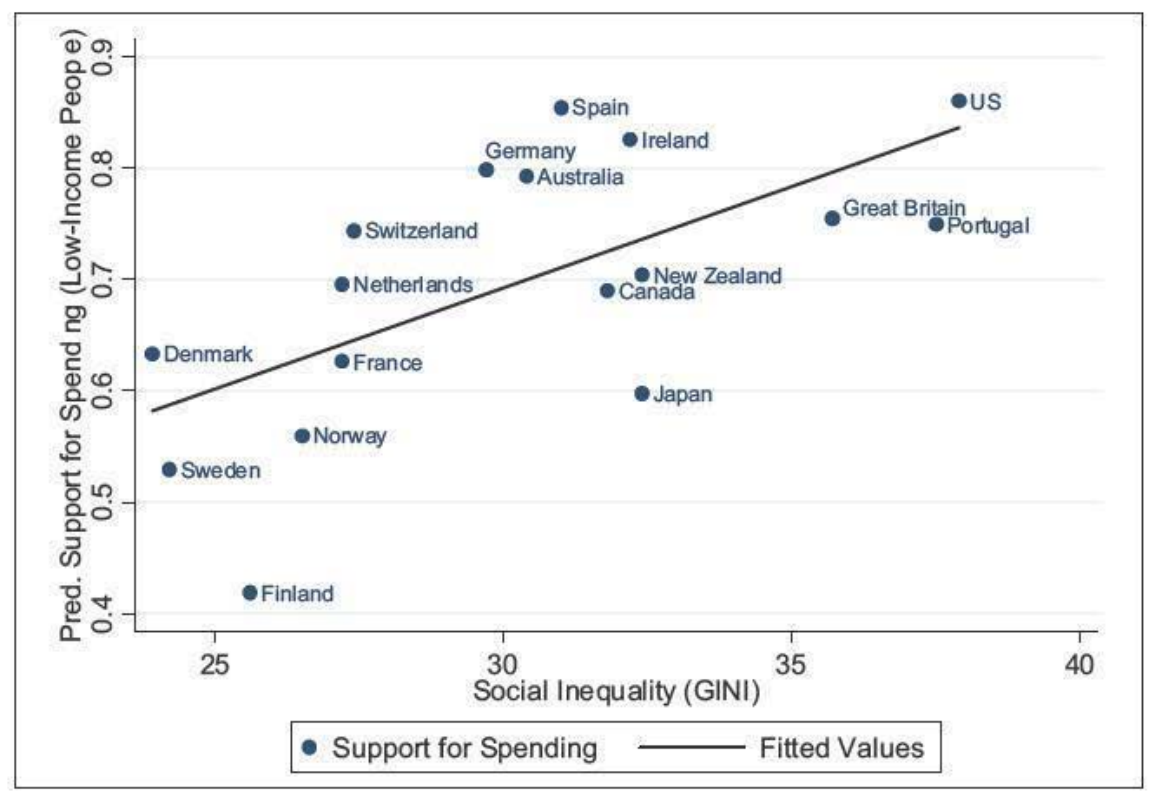

Figure 3. The association between socio-economic inequality and levels of support for public education spending.

Considering the joint impact of all significant predictors, the predicted probability of supporting increased government spending on education for men with little education and no children is $62.95 \%$ (which is still high, showing that education spending is popular). For a well-educated female student with children, however, the predicted probability is a massive $79.89 \%$.

Coming to the macro-level variables, Model 2 exhibits a significantly positive association between individual support for education spending and levels of socio-economic inequality, as expected. Based on estimates from the first stage of the two-step hierarchical estimation procedure, Figure 3 documents this positive association. The United States and Great Britain, but also Portugal, are characterized by high levels of socio-economic inequality and high levels of support for increases in public education spending, whereas the opposite holds true for the Scandinavian countries. Thus, an increase in socioeconomic inequality leads to an increase in the demand for redistributive public spending, as expected from the Meltzer-Richard model. In contrast, educational inequality does not have a direct effect on support for increased education spending.
Furthermore, the current level of education spending does not have a strong impact on average levels of support either. The sign of the coefficient estimate is negative, as would be expected from the 'public as thermostat' theory (Wlezien, 1995), but the effect is not robust across model specifications.

Most importantly, Table 1 presents strong evidence on the cross-level interaction beteween the effect of the individual income position and institutional contexts. When the general level of socioeconomic inequality increases, the income effect becomes more negative. This means that the severity of the conflict over increases in public education spending based on income differences increases. The effect of educational inequality, in contrast, works in the opposite direction. Higher levels of educational inequality mitigate the income effect at the micro level, that is the cross-level interaction is positive. This is because higher levels of educational inequality imply that access to higher levels of education is more restricted for people with a weak socio-economic background, leading to reduced support for more education spending among the poor and increased support among the well-off. 
Table 2. Results from the second stage of the two-step hierarchical estimation procedure

\begin{tabular}{lcc}
\hline & $(1)$ & $(2)$ \\
\cline { 2 - 3 } Dependent variable & Country-specific income coefficient & \\
\hline Educational inequality & $0.13289 * *(0.0543)$ & $0.1069(0.0989)$ \\
Socio-economic inequality & $-0.0079 *(0.003 \mathrm{I})$ & $-0.0088 * *(0.0033)$ \\
Constant & & $0.0744(0.1905)$ \\
Observations & 17 & 17 \\
$r^{2}$ & 0.27 & 0.27 \\
\hline Robust standard errors in parentheses. & & \\
$* p<0.1$, **p $<0.05, * * * k p<0.01$. &
\end{tabular}

Models 2 to 7 in Table 1 demonstrate the robustness of these findings. In Models 2 and 3, educational and socio-economic inequality and their interaction with income at the micro level are included seperately. In Model 4, they are included jointly. The sign and statistical significance of the coefficient estimates remain robust across model specifications. In Models 5 and 6 , I rely on alternative measures of eduational inequality. The measure of educational inequality developed by Pfeffer (2008) performs equally to the OECD measure, although the size of the sample is reduced significantly because this indicator is only available for a subset of countries. Model 6 includes net enrolment in tertiary education as an indirect measure of educational inequality. Here the assumption is that higher rates of net enrolment indicate less severe barriers of access to higher levels of education, that is less educational inequality. Therefore, the sign of the coefficient is reversed in comparison with the other measures used. Nevertheless, we also find a statistically significant association in the expected direction. Model 7, finally, includes country dummies instead of macro-level variables. Again, the magnitude, sign and statistical significance of the cross-level interactions remain virtually constant. All in all, therefore, there is strong evidence that suggests that socio-economic and educational inequality both have a distinct impact on the microlevel dynamics of individual preferences of education spending.

It is important to note, however, that the sign of the direct effect of income changes across models, depending on which cross-level interactions are included. By looking at the coefficient estimates of Table 1, it cannot be seen immediately how strongly the cross-level interactions influence the direct effect of income. At this point, the two-step hierarchical estimation procedure proves helpful, because it allows a very intuitive and non-technical presentation of complex interactive effects.

Figure 4 presents estimates of the size of the income effect in the countries covered in the survey. More specifically, each bar represents the estimated change in the predicted probability of supporting increases in public education spending when moving from an individual at an income position one standard deviation below the mean to an individual at an income position one standard deviation above the mean. As can be seen, the variation in the size and direction of this income effect across countries is significant. In some countries, such as Great Britain, France, Japan and the United States, an increase in income results in a decrease in the support for more education spending. In contrast, in Norway, Switzerland and Germany, a comparable increase in the income position leads to an increase in the support for public education spending.

This cross-national variation in the size and direction of the income effect is captured by the crosslevel interactions. As a complement to Table 1, Table 2 presents the results of the second stage of the twostep hierarchical estimation procedure. The findings presented in this table confirm that inequality and educational stratification significantly shape the 


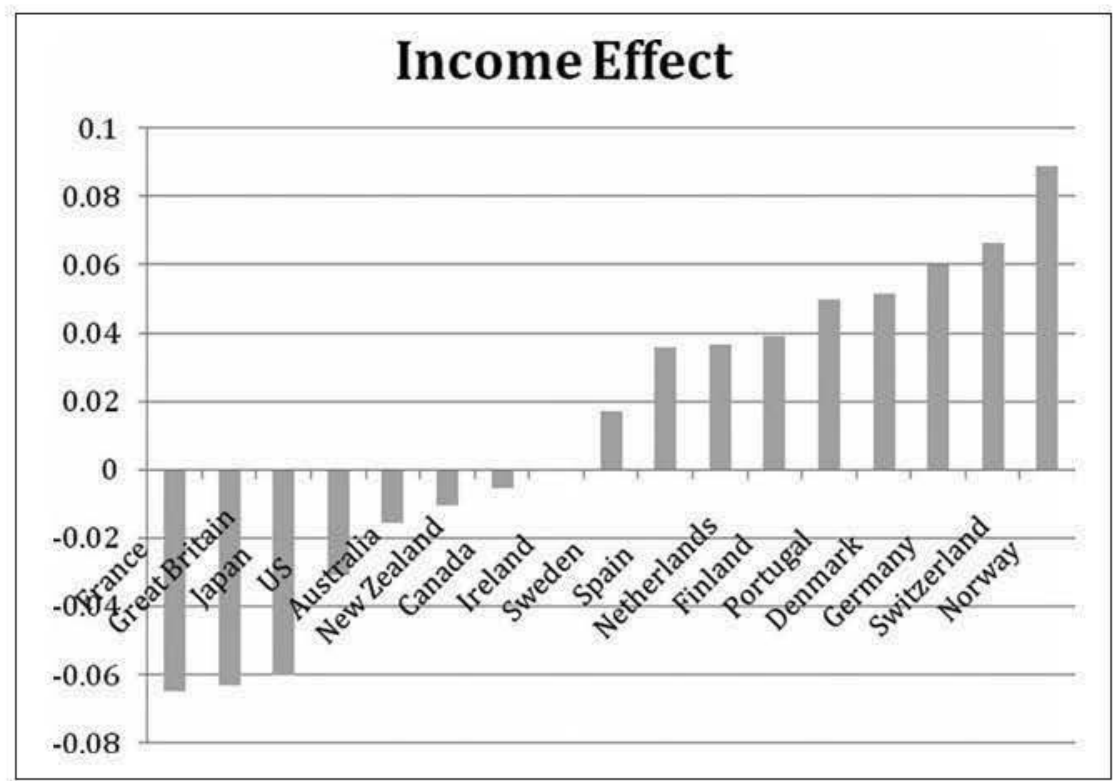

Figure 4, Estimates of the size of the income effect for 17 OECD countries.

Predicted changes in support for increased education spending when moving from one country-specific standard deviation below the mean to one standard deviation above the mean.

relationship between income and support for spending on the micro level. Including both educational and socio-economic inequality in the same model (Model 1) leads to statistically significant effects on the 0.05 level and an $R^{2}$ value of 0.27 , which is considerable given that this is a purely cross-sectional regression with 17 cases. When a constant is included, the significance of the coefficient estimate of educational inequality drops below conventional levels. However, the constant itself is insignificant too.

Based on Model 1, it is possible to estimate the effect of these variables on income. An increase in socio-economic inequality comparable to the real difference between Denmark and the United States (about 14 points in the Gini index) is associated with a decrease in the size of the income effect of 0.056 . This in turn implies that in countries with high levels of inequality, the decrease in support for education spending resulting from a move up the income ladder by one unit is 5.6 percentage points more than in countries with low levels of inequality. In contrast, an increase in the measure of educational inequality by one unit (that is, roughly the difference between Denmark and
Germany) increases the size of the income effect by 0.07 . Thus, a similar improvement in the income position as in the previous example would lead to an increase of seven percentage points in the support for public education spending in highly stratified education systems.

Figures 5 and 6 makes these complex relationships more tangible. Figure 5 documents the positive association between educational inequality and the size of the income effect. When levels of educational inequality are high, the income effect turns positive, that is the rich/poor are more likely to support/ oppose increases in public spending. In contrast, Figure 6 displays the negative association between socio-economic inequality and the micro-level income effect. In line with the theoretical expectations, increases in socio-economic inequality are associated with a more negative income effect, that is support/opposition for increases in public education spending increases among the poor/rich. In the graphical representation, Germany seems to occupy an outlier position (to some extent this is true for Switzerland as well). Further robustness tests (available from the author upon request) show, however, 


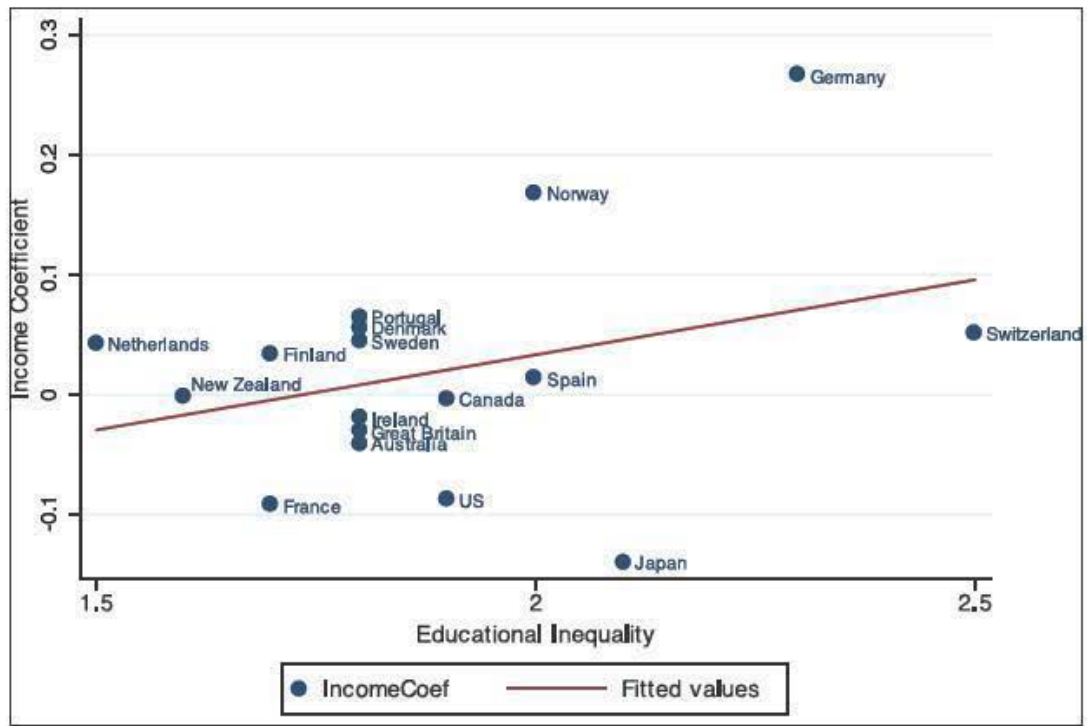

Figure 5. Relationship between the size of the income coefficient and educational inequality.

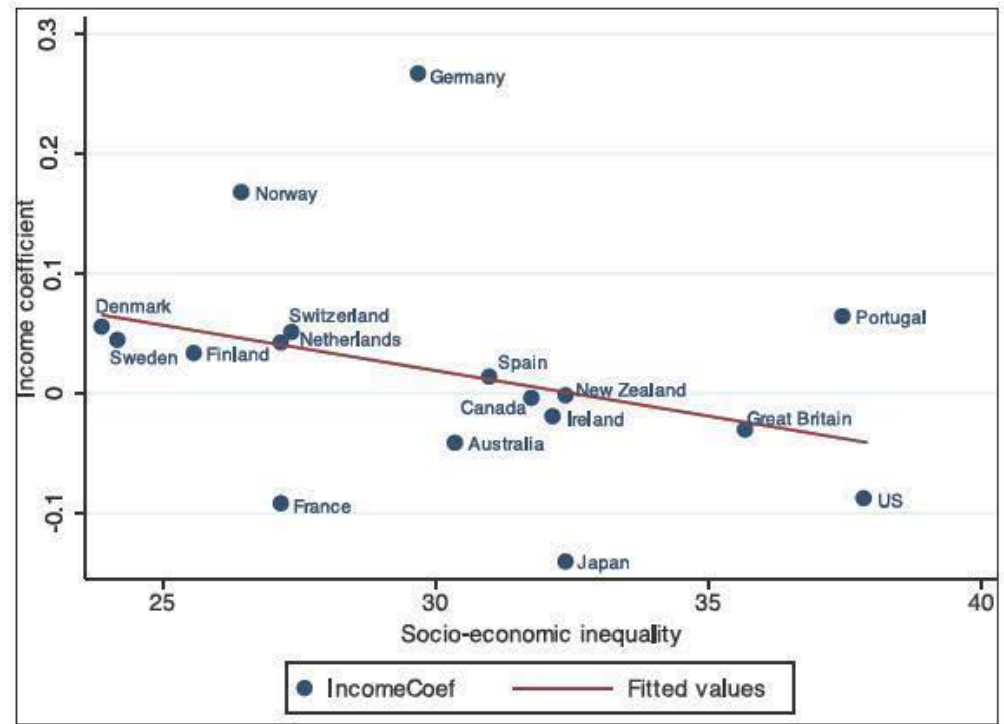

Figure 6. Relationship between the size of the income coefficient and socio-econmic inequality.

that excluding Germany does not alter the main findings in any significant way. The magnitude of the coefficient of the educational inequality variable decreases slightly but remains statistically significant.
All in all, using various graphical and statistical techniques and model specifications, I find considerable evidence for the presence of cross-level interaction effects, although the relationships vary in strength. 


\section{Discussion and conclusions}

This paper speaks to current debates in the political economy of redistribution and skill formation. By looking at the case of education, it aims to make a more general point: when studying the formation of preferences for redistribution at the micro level, it is necessary to take into account cross-level interactions with the macro level. Institutions and socioeconomic contexts shape the relative pay-off of particular policies, and therefore levels of support for or opposition to increases in public spending as well. Hence, the present study complements and expands existing research on the dynamics of public opinion, which is often more concerned with analysing associations at the micro level.

More specifically, I have shown that socioeconomic and educational inequality are both important factors shaping the dynamics at the micro level. Interestingly, there is no strong association between the two on the macro level. As a first step towards a more comprehensive understanding of the relationship between educational and socio-economic inequality, the study of cross-level interactions of these two dimensions of inequality with individual income reveals very different dynamics. Higher levels of socio-economic inequality increase overall support for education spending and lead to a more negative effect of income on support for spending increases. These findings are mostly to be expected from the perspective of the Meltzer-Richard model. The contribution of the paper - besides studying individual preferences for education spending more generally - is to look at the impact of educational inequality, which works in the opposite direction and thus runs counter to the logic of Meltzer and Richard (1981). I find strong evidence that increasing levels of educational inequality have a positive effect on the size of the income effect at the micro level. When access to higher levels of education is effectively restricted, an increase in income actually leads to an increase in support for more education spending. This is because higher levels of educational stratification ensure that further public investments in education benefit the rich relatively more than the poor, who become less willing to support this kind of public spending.
The findings of this paper also have implications for the politics of reforming contemporary welfare states and education systems. It is a well-known finding in the literature that the dynamics of public opinion are connected in various ways to actual policy-making. Policy-makers are very sensitive to what the public thinks (Wlezien, 1995), which affects the leeway for policy reforms. For example, I have shown that the level of general support for expanding public education is higher in countries with high levels of socio-economic inequality. Thus, following in the footsteps of Heidenheimer (1981), expanding the education state could serve as a functional equivalent to welfare state expansion, where the latter is politically not feasible.

However, a further policy implication of my findings is that the connection between socio-economic and educational inequality is far less straightforward than could be expected. In that sense, education cannot be regarded as a simple functional equivalent to other, more redistributive, kinds of social transfers. The extent to which increased investments in education decrease socio-economic inequality strongly depends on the institutional context, that is the specific set-up of the education system and supporting labour market institutions. A full treatment of this issue remains beyond the scope of this paper but should be further addressed in future research.

A third implication of my findings is that the strategies of political parties with regard to the expansion of education should vary across institutional contexts. As has been shown, support for increasing public education spending among the rich is higher in stratified education systems than in egalitarian ones. In line with Ansell's (2008) findings on higher education, leftist parties as representatives of the interests of the low-income classes should therefore be more hesitant to expand education spending as long as educational inequalities are high, whereas rightist parties are more willing to increase spending (Jensen, 2011) under these circumstances. In contrast, when educational inequality is low, the conflict over investments in education starts to resemble a more typical conflict over redistribution, reinstating the classical partisan positions. The present study thus complements existing research on the partisan politics of education spending (Ansell, 2008; 
Busemeyer, 2007, 2009; Jensen, 2011; Schmidt, 2007) by providing micro-level evidence for cleavages in public opinion that fit with observed differences in partisan strategies across countries.

To outline avenues for future research, the argument presented in this paper can be extended beyond the case of education for other kinds of redistributive policies. Essentially, the argument implies that two factors shape the political economy of redistribution at the micro level: the general level of socioeconomic inequality, and the more specific degree of redistribution associated with the particular policy in question. In the present case, this is education, but it is well known in the welfare state literature that other social policies such as pensions or labour market policies can be more or less redistributive, depending on the country context. Hence, future research could compare the impact of general levels of inequality and policy-specific stratification on individual preferences for a range of social policies (see, for example, McCall and Kenworthy, 2009). Also, it would be important to distinguish between different kinds of education (that is vocational training, academic education). Unfortunately, the ISSP data used in this paper do not allow this distinction. Using a survey from Switzerland, Busemeyer et al. (2011) were able to present some first evidence of the different determinants of support for investments in vocational and academic education. Obviously, it would be very worthwhile to extent this kind of analysis to the international level.

\section{Acknowledgements}

Previous versions of this paper were presented at the Center for European Studies at Harvard University, at the Comparative Politics Seminar at Duke University, at the Workshop on 'Welfare state traditions, education and higher education policies' at the University of Konstanz, as well as in the form of invited talks at the University of Bern and the Central European University in Budapest. I would like to thank the participants of all these events and others for helpful comments and suggestions, in particular Achim Goerres, Daniel Horn, Timo Idema, Torben Iversen, Herbert Kitschelt, Andrew Martin, Erik Wibbels and Carsten Q. Schneider. I would also like to thank the anonymous reviewers and the editors of this journal for their input.

\section{Funding}

This research was in part supported by a grant from the German Research Foundation (DFG) for the project "The Politics of Education and Training Reforms in Western Welfare States.

\section{Notes}

1. In a similar tone, Boix (1998: 37$)$ argued that the supporters of the left in the lower-income classes care more about investments in general education at the primary and secondary levels, such as vocational training, although he was not able to show this empirically owing to data limitations.

2. In fact, including partisan ideology as an additional micro-level variable does not alter the statistical significance or sign of the other coefficients in any meaningful way. A more practical reason against the inclusion of partisan identification is that it significantly reduces the size of the sample.

3. The estimates of the main variables of interest are essentially the same (results available from the author). The problem with using age instead of the 'retired' dummy is that age is also correlated with having children. Therefore, I decided to use a categorical operationalization of labour market status instead of continuous variables.

4. This operationalization is a more encompassing operationalization of 'outsiderness' than when simply using employment status. The latter is also possible and does not change the results of the main variables in any significant manner. I also looked at employment in the public sector as an additional control variable. As could be expected, this variable turns out to be a positive and significant predictor of support for spending. However, the limited availability of data reduces the number of observations by about $50 \%$. Given the focus of the paper on cross-level interactions rather than micro-level dynamics as such, I decided to drop this variable.

5. Another alternative measure would be the strength of the association between individual socio-economic background and educational attainment of students (provided in the PISA studies). I decided against using this measure because, in contrast to the odds measure used here, it is not correlated with the other measures of educational inequality. Furthermore, the preferred OECD measure reflects to a stronger extent the impact 
of the institutional set-up of post-secondary education on the educational expectations of parents and children ('secondary effects'), whereas the PISA measure captures the primary effects (the association between socio-economic background and educational attainment). I also decided against using institutional indicators of the structure of the secondary education system as indicators of educational inequality, because these usually remain on a highly aggregated level and blend over important differences in the real effects of institutions on outcomes.

6. Including age and age squared instead of the dummy variable reveals an interesting curvilinear pattern: support for increasing education spending first increases with age, then declines (not shown here). Because age is simply included as a control variable in the present paper, the exploration of this pattern has to be left to future research.

\section{References}

Achen, C. (2005) 'Two-Step Hierarchical Estimation: Beyond Regression Analysis', Political Analysis 13(4): 447-56.

Allmendinger, J. (1989) 'Educational Systems and Labour Market Outcomes', European Sociological Review 5(3): 231-50.

Ansell, B.W. (2008) 'University Challenges: Explaining Institutional Change in Higher Education', World Politics 60(January): 189-230.

Ansell, B.W. (2010) From the Ballot to the Blackboard: The Redistributive Political Economy of Education. Cambridge: Cambridge University Press.

Arts, W. and Gelissen, J. (2001) 'Welfare States, Solidarity and Justice Principles: Does the Type Really Matter?' Acta Sociologica 44(4): 283-99.

Becker, R. and Hecken, A.E. (2009) 'Higher Education or Vocational Training? An Empirical Test of the Rational Action Model of Educational Choices Suggested by Breen and Goldthorpe and Esser', Acta Sociologica 52(1): 25-45.

Bernasconi, M. and Profeta, P. (2007) 'Redistribution or Education? The Political Economy of the Social Race', CESifo Working Paper 1934.

Blekesaune, M. and Quadagno, J. (2003) 'Public Attitudes toward Welfare State Policies: A Comparative
Analysis of 24 Countries', European Sociological Review 19(5): 415-27.

Boix, C. (1997) 'Political Parties and the Supply Side of the Economy: The Provision of Physical and Human Capital in Advanced Economies, 1960-1990', American Journal of Political Science 41(3): 814-45.

Boix, C. (1998) Political Parties, Growth and Equality: Conservative and Social Democratic Economic Strategies In The World Economy. Cambridge: Cambridge University Press.

Boudon, R. (1974) Education, Opportunity, and Social Inequality. New York: Wiley.

Bradley, D., Huber, E., Moller, S., Nielsen, F. and Stephens, J.D. (2003) 'Distribution and Redistribution in Postindustrial Democracies', World Politics 55(January): 193-228.

Breen, R. and Goldthorpe, J.H. (1997) 'Explaining Educational Differentials: Towards a Formal Rational Action Theory', Rationality and Society 9: 275-305.

Breen, R. and Jonsson, J.O. (2005) 'Inequality of Opportunity in Comparative Perspective: Recent Research on Educational Attainment and Social Mobility', Annual Review of Sociology 31: 223-43.

Breen, R., Luijkx, R., Müller, W. and Pollak, R. (2009) 'Nonpersistent Inequality in Educational Attainment: Evidence from Eight European Countries', American Journal of Sociology 114(5): 1475-521.

Busemeyer, M.R. (2007) 'The Determinants of Public Education Spending in 21 OECD Democracies, 1980 2001', Journal of European Public Policy 14(4): $582-610$.

Busemeyer, M.R. (2009) 'Social Democrats and the New Partisan Politics of Public Investment in Education', Journal of European Public Policy 16(1): 107-26.

Busemeyer, M.R. and Jensen, C. (2010) 'Capitalist Systems and Education Policy Preferences', paper presented at the Conference of the Council for European Studies, Montreal, Canada, April 2010.

Busemeyer, M.R., Cattaneo, M.A. and Wolter, S.C. (2011) 'Individual Policy Preferences for Vocational versus Academic Education: Micro Level Evidence for the Case of Switzerland', Journal of European Social Policy 21(3): 253-73.

Busemeyer, M.R., Goerres, A. and Weschle, S. (2009) 'Attitudes Towards Redistributive Spending in an Era of Demographic Ageing: The Rival Pressures from 
Age and Income in 14 OECD Countries', Journal of European Social Policy 19(3): 195-212.

Cattaneo, M.A. and Wolter, S.C. (2007) 'Are the Elderly a Threat to Educational Expenditures?' CESifo Working Paper 2089.

Corneo, G. and Grüner, H.P. (2002) 'Individual Preferences for Political Redistribution', Journal of Public Economics 83: 83-107.

Cusack, T., Iversen, T. and Rehm, P. (2006) 'Risks at Work: The Demand and Supply Sides of Government Redistribution', Oxford Review of Economic Policy 22(3): 365-89.

Duch, R.M. and Stevenson, R. (2005) 'Context and the Economic Vote: A Multilevel Analysis', Political Analysis 13(4): 387-409.

Estevez-Abe, M., Iversen, T. and Soskice, D. (2001) 'Social Protection and the Formation of Skills: A Reinterpretation of the Welfare State', in P.A. Hall and D. Soskice (eds) Varieties of Capitalism: The Institutional Foundations of Comparative Advantage. Oxford, New York: Oxford University Press, pp. 145-83.

Fernandez, R. and Rogerson, R. (1995) 'On the Political Economy of Education Subsidies', Review of Economic Studies 62(2): 249-62.

Goerres, A. and Tepe, M. (2010) 'Age-based Self-interest, Intergenerational Solidarity and the Welfare State: A Comparative Analysis of Older People's Attitudes Towards Public Childcare in 12 OECD countries', European Journal of Political Research 49(6): 818-51.

Gradstein, M. and Kaganovich, M. (2004) 'Aging Population and Education Finance', Journal of Public Economics 88: 2469-85.

Hasenfeld, Y. and Rafferty, J.A. (1989) 'The Determinants of Public Attitudes Toward the Welfare State', Social Forces 67(4): 1027-48.

Heidenheimer, A.J. (1981) 'Education and Social Security Entitlements in Europe and America', in P. Flora and A.J. Heidenheimer (eds) The Development of Welfare States in Europe and America (pp. 269-304). New Brunswick, London: Transaction Books.

Huber, J.D., Kernell, G. and Leoni, E.L. (2005) 'Institutional Context, Cognitive Resources and Party Attachments Across Democracies', Political Analysis 13(4): 365-86.

Idema, T. (2010) 'Core Voters, Swing Voters and the Distributive Politics of Higher Education', paper presented at the workshop 'Welfare State Traditions,
Education and Higher Education Policy', University of Konstanz, Germany. May 2010.

Iversen, T. (2005) Capitalism, Democracy, and Welfare. Cambridge: Cambridge University Press.

Iversen, T. and Soskice, D. (2001) 'An Asset Theory of Social Policy Preferences', American Political Science Review 95(4): 875-93.

Iversen, T. and Soskice, D. (2006) 'Electoral Institutions and the Politics of Coalitions: Why Some Democracies Redistribute More Than Others', American Political Science Review 100(2): 165-81.

Iversen, T. and Soskice, D. (2009) 'Distribution and Redistribution: The Shadow of the Nineteenth Century', World Politics 61(3): 438-86.

Iversen, T. and Stephens, J.D. (2008) 'Partisan Politics, the Welfare State, and Three Worlds of Human Capital Formation', Comparative Political Studies 41(4-5): 600-37.

Jaeger, M.M. (2009) 'United but Divided: Welfare Regimes and the Level and Variance in Public Support for Redistribution', European Sociological Review 25(6): 723-37.

Jensen, C. (2011) 'Capitalist Systems, De-industrialization, and the Politics of Public Education', Comparative Political Studies 44 (4): 412-35.

Kitschelt, H. and Rehm, P. (2006) 'New Social Risk and Political Preferences', in K. Armingeon and G. Bonoli (eds) The Politics of Post-Industrial Welfare States: Adapting Post-War Social Policies to New Social Risks. New York: Routledge, pp. 52-82.

Levy, G. (2005) 'The Politics of Public Provision of Education', Quarterly Joumal of Economics 120(4): 1507-34.

Lewis, J.B. and Linzer, D.A. (2005) 'Estimating Regression Models in Which the Dependent Variable is Based on Estimates', Political Analysis 13(4): 345-64.

Lynch, J. and Myrskylä, M. (2009) 'Always the Third Rail? Pension Income and Policy Preferences in European Democracies', Comparative Political Studies 42(8): 1068-97.

McCall, L. and Kenworthy, L. (2009) 'Americans' Social Policy Preferences in the Era of Rising Inequality', Perspectives on Politics 7(3): 459-84.

Meltzer, A.H. and Richard, S.F. (1981) 'A Rational Theory of the Size of Government', Journal of Political Economy 89(5): 914-27. 
Moene, K.O. and Wallerstein, M. (2001) 'Inequality, Social Insurance, and Redistribution', American Political Science Review 95(4): 859-74.

Moene, K.O. and Wallerstein, M. (2003) 'Earnings Inequality and Welfare Spending: A Disaggregated Analysis', World Politics 55(4): 485-516.

Organisation for Economic Co-operation and Development (OECD) (2007) Education at a Glance 2007: $O E C D$ Indicators. Paris: OECD.

Rehm, P. (2009) 'Risk and Redistribution: An Individual-Level Analysis', Comparative Political Studies 42(7): 855-81.

Pfeffer, F. (2008) 'Persistent Inequality in Educational Attainment and Its Institutional Context', European Sociological Review 24(5): 543-565.

Scheve, K. and Stasavage, D. (2006) 'Religion and Preferences for Social Insurance', Quarterly Journal of Political Science 1: 255-86.

Schlicht, R., Stadelmann-Steffen, I. and Freitag, M. (2010) 'Educational Inequality in the EU: The Effectiveness of National Education Policy', European Union Politics 11(1): 29-59.

Schmidt, M.G. (2007) 'Testing the Retrenchment Hypothesis: Educational Spending, 1960-2002', in F.G. Castles (ed.) The Disappearing State? Retrenchment Realities in an Age of Globalisation. Cheltenham, Northampton: Edward Elgar, pp. 159-83.

Solt, F. (2009) 'Standardizing the World Income Inequality Database', Social Science Quarterly 90(2): 231-42.

Svallfors, S. (1997) 'Worlds of Welfare and Attitudes to Redistribution: A Comparison of Eight Western Nations', European Sociological Review 13(3): 283-304.

Svallfors, S. (2004) 'Class, Attitudes and the Welfare State: Sweden in Comparative Perspective', Social Policy and Administration 38(2): 119-38.

Wlezien, C. (1995) 'The Public as Thermostat: Dynamics of Preferences for Spending', American Journal of Political Science 39(4): 981-1000. 